\title{
Intern doctors' views on the current and future antibiotic resistance situation of Chattagram Maa O Shishu Hospital Medical College, Bangladesh
}

This article was published in the following Dove Press journal:

Therapeutics and Clinical Risk Management

II August 2015

Number of times this article has been viewed

Rozina Hoque'

Asma Mostafa ${ }^{2}$

Mainul Haque

'Department of Pharmacology, ${ }^{2}$ Department of Anatomy, Chattagram Maa O Shishu Hospital Medical College, Agrabad, Chittagong, Bangladesh; ${ }^{3}$ Unit of Pharmacology, Faculty of Medicine, Universiti Sultan Zainal Abidin, Terengganu, Malaysia

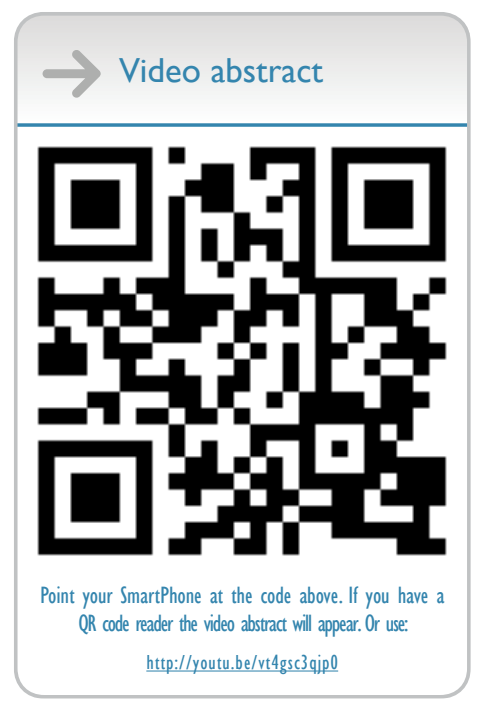

Correspondence: Mainul Haque Faculty of Medicine, Universiti Sultan Zainal Abidin, Kampus Kota, Jalan Sultan Mahmud, 20400 Kuala Terengganu,

Terengganu, Malaysia

Tel +60 I 09265543

Email runurono@gmail.com
Background: Bacterial resistance due to antibiotic misuse is reported every day. Such threat calls for a consensus to develop new strategies to prevent the development of antibiotic resistance of bacteria. Medical doctors must play a pivotal role to control and prevent the misuse of antibiotics. There were complaints that prescribers are lacking behind in updates and advancement in the field. To address such knowledge gap, a study was conducted to know the views of interns on the current antibiotic resistance situation in a teaching hospital in Bangladesh.

Methods: This study was a cross-sectional, randomized, and questionnaire-based survey. Interns of the medicine, gynecology, and surgery departments of Chattagram Maa O Shishu Hospital Medical College were the study population.

Results: Out of 50 respondents, $98 \%$ would like more education on antibiotic selection. All respondents believed that prescribing inappropriate or unnecessary antibiotics was professionally unethical. Ninety percent of the participants were confident in making an accurate diagnosis of infection. Eighty-four percent of them were confident about dosage schedule. In all, $98 \%$ participants thought that antibiotic resistance is a national problem and $64 \%$ of the respondents thought that same problem also existed in their hospital. Study participants were of the view that $41 \%-60 \%$ of antibiotic usages are irrational in Bangladesh. Fifty-eight percent of the study population thought that antimicrobial resistance (AR) would be a greater problem in the future.

Conclusion: The interns believe that there is a knowledge gap on AR. More emphasis should be given to AR and its implications in the undergraduate curriculum. Latest national and international guidelines for antimicrobial therapy and resistance should be made available to the interns.

Keywords: interns, antibiotic, prescribing, resistance, Bangladesh, knowledge, perception

\section{Introduction}

Antimicrobials are the most commonly prescribed drugs in general and institutional practice. ${ }^{1}$ During the internship, the clinical knowledge of the physician is like the moulding of soil to make the desirable shaped pot. During this period of training, the interns can be exposed to good prescribing practices by clinicians with knowledge about antibiotic prescription and antimicrobial resistance (AR). Infectious diseases remain a priority public health problem despite the improved trend of health care in Bangladesh. ${ }^{2}$ The use of antimicrobials to treat bacterial, fungal, viral, and parasitic infections is unavoidable. A majority of the doctors in Bangladesh diagnose an infection by clinical assessment and conduct laboratory tests to identify suspected microbes. Antimicrobials are sometimes prescribed based on best-guess empiric therapy. ${ }^{2}$ A study conducted in Bangladesh also reported that there was no uniformity in prescription 
for commonly prevalent infections, for example, malaria, kala-azar, and tuberculosis. ${ }^{2}$ The same study also observed that completion of the course of prescribed antibiotic was not supervised, which led to poor compliance and thus promotes and facilitates AR. ${ }^{2}$ AR is a mounting problem in health care both globally and locally in Bangladesh. During the last 70 years, the development of effective antimicrobials has reduced incidence of life-threatening infections; however, that achievement has steadily been eroded by the emergence of resistance. ${ }^{3}$ Microbes developed resistance largely in hospitals, which later spread in the community, imposing more risk to human health. Infections with resistant microbes not only result in greater morbidity and mortality, but also increase the health care costs. The loss of effectiveness of the antimicrobials leads to the need of more research as well as increased development expenses. ${ }^{4}$

The development of AR is accelerated by excessive antimicrobial prescriptions. ${ }^{5}$ More than $50 \%$ of antibiotics worldwide can be purchased without a prescription. ${ }^{6-8}$ The scenario in developing countries is worse as regulatory measures are poorer with regard to antibiotic use and sales. In many undeveloped countries, the latest antimicrobials are also available over-the-counter ${ }^{9}$ and patients take the opportunity to self-prescribe due to high consultation cost. ${ }^{7,10}$ To mitigate AR, there is an urgent need to transform the attitude of not only medical doctors but also all other health professionals regarding prescribing antimicrobials. ${ }^{7}$ Paramedical staff in hospitals can play an important role in preventing the transmission of resistant bacteria and promote the awareness of AR to patients and the community, together with the physicians and nurses, and thus, a more effective intervention to control of AR can be strategized. ${ }^{7,11-14}$ In all, 20\%-50\% of antibiotic use is either unnecessary or inappropriate, ${ }^{15-17}$ and decreasing it is a necessary first step to restrain antibiotic resistance. ${ }^{17,18}$ There are reports indicating that often national, international, and hospital guidelines were not enough to change medical doctors' behavior regarding antimicrobial prescribing. ${ }^{19}$

Although AR is now a global public health issue, there is no major advancement in tackling such an imperative health threat. ${ }^{13,20}$ To combat a potentially devastating problem, physicians' knowledge and awareness need to be updated. ${ }^{12-14,17,21-23}$ It has been recommended that to achieve the goal a baseline study is absolutely necessary regarding the knowledge and attitude of fresh medical graduates toward AR. ${ }^{17,23}$ Medical doctors are responsible for not only prescribing and promoting rational use of medication but can also educate the patients about AR. ${ }^{24,25}$
Poor training during their undergraduate and postgraduate years may contribute to their incompetence in choosing the right medication for the patient. ${ }^{26}$ Hence, teaching pharmacology and therapeutics should be considered an important issue in any medical school to promote right prescription for right patient and enhance rational and evidence-based antimicrobial therapy. ${ }^{25,26}$ More emphasis on the risk of AR and rational prescribing should be given to medical students and young graduates. ${ }^{27}$ It is during their training years that they are most amenable to good prescribing practices and it is believed that once a bad habit develops it is very difficult to rectify. ${ }^{27}$ Medical doctor's houseman-ship or foundation years are basically an intermediate period between graduation and practicing independently. ${ }^{28}$ The important goal for any medical school pharmacology curriculum is to teach rational and evidence-based prescribing. ${ }^{28}$ Proper teaching Clinical Pharmacology and Therapeutics (CPT) will promote rational use of medicine as it ensures acquiring these competencies. ${ }^{28}$ Unfortunately, the emphasis and focus on CPT teaching is lost during postgraduation training. The first prescription by the medical students begins during the internship. However, inadequate CPT training has been found to be responsible for a significant number of prescribing errors. ${ }^{29-31}$

In many countries, microbial diseases are still a predominant public health threat but on the other hand indiscriminate use of antibiotics promotes resistance. Therefore, prescribers must weigh the benefits and risk to minimize the development of resistance. ${ }^{32}$ As high as $50 \%$ of health professionals including medical doctors were often blamed for irrational use of antimicrobials. ${ }^{33}$ Previous studies reported the lack of knowledge on the magnitude and causes of resistance, as well as a poor correlation between knowledge and practice. . $^{13,34}$ The information gained can be used in designing more effective antibiotic control interventions and educational programs.

To the best of our knowledge, there is no previous study on the attitude and perception of intern doctors regarding AR in Bangladesh. However, there was a study on the assessment of interns' knowledge regarding pharmacology and therapeutics. ${ }^{31}$ So, from this study, data on their existing knowledge about antibiotics will be collected and the information be used to plot a future plan to upgrade their knowledge and training. Therefore, authority can set up the guideline for them to prescribe $\mathrm{P}$ drug. This study will identify any gaps in the knowledge regarding antibiotic prescription by intern doctors in Bangladesh.

\section{Materials and methods}

This study was a cross-sectional, randomized, questionnairebased survey, which was undertaken in Chattagram Maa O 
Shishu Hospital Medical College (CMOSHMC), Chittagong, Bangladesh. The interns of the departments of medicine, gynecology, and surgery of this medical college were the study population. Data were collected using a validated instrument. The corresponding author was impressed with the multicenter study conducted in Europe. ${ }^{35}$ He contacted the lead researcher in France and obtained formal permission to use the validated instrument. The questionnaire was again pretested and validated for the local context. The questionnaire was administered to 16 interns who did not participate in the main study. Their responses were collected and analyzed for validity and reliability. The chronbach alpha was calculated as 0.69 . In all, 50 out of 66 interns who did not participate in the validation process were selected randomly in the study of the stated hospital. All of the respondents were given a questionnaire in their off time that was prearranged. They were asked to complete the questionnaire anonymously. Data were collected in March 2015. The filled-in copies were handed over immediately to the principal investigator. The final questionnaire consisted of 21 questions. Initially, demographic features were recorded. The first question was a 5-point Likert scale, where responses ranged from "very unconfident" to "uncertain". It was used to assess intern's confidence in prescribing. Six questions were set to have the idea of training in antibiotic prescribing. Out of six, five questions were arranged in Likert scale-based questions with options of "yes", "no", and "unsure". One question was to assess the total hours of training the interns have received during their undergraduate study. Then, the successive five questions were set to assess the intern's knowledge on AR. Two of these were set out so as to put a tick mark for "yes", "no", or "unsure". The other three questions were arranged in six rows, which indicated the percentage range in the following manner: row 1 was $<1 \%$, row 2 was $1 \%-20 \%$, row 3 for $21 \%-40 \%$, row 4 for $41 \%-60 \%$, row 5 included $61 \%-80 \%$, and the last row showed $\%$ range from $81 \%$ to $100 \%$. The self-reported practices regarding the antibiotic usage of the study population were also assessed by using two questions that consisted of five rows. Each row showed the percentage range in the answer. Ranges of percentage were $1 \%-20 \%$ in the first row, $21 \%-40 \%$ in the second row, $41 \%-60 \%$ in the third row, $61 \%-80 \%$ in the fourth row, and finally $81 \%-100 \%$ in the fifth row. The interns perception about the contributors to antibiotic resistance was assessed by another question which consisted of a 4-point Likert scale, whose responses ranged from "very important" to "not important at all". The next two knowledge-based questions were about the number of new classes of antibiotics that became clinically available in the last 30 years as well as those that will become available in the next 30 years. The last three questions were used to assess the perceptions of antibiotic resistance of the participants.

Research ethics was strictly maintained. Informed consent was obtained verbally from the participants to utilize their data for research purposes. Before performing the study, an institutional ethical clearance certificate was obtained (Institutional Review Board memo number 01, 7 April, 2015). The research and ethical committee of Chattagram Maa O Shishu Hospital Medical College, (Chittagong, Bangladesh) gave verbal permission to collect the data prior to issuance of the certificate. Simple descriptive statistics was used to generate frequencies and percentages.

\section{Results \\ Demographic profile}

There were 66 intern doctors in different departments of the teaching hospital of CMOSHMC during the period of study. Fifty participants (24\% male and $76 \%$ female) responded to the questionnaire. Among the respondents, 30\% were between the age range of 22-24 years and the rest of them were between the age range of 25-28 years (Table 1).

\section{Levels of confidence in prescribing}

The participants felt most confident in "making an accurate diagnosis of infection/sepsis" (90\%), "choosing the correct dose and interval of administration" (84\%), and "planning the duration of the antibiotic treatment" $(84 \%)$. The respondents felt least confident in "using a combination therapy if appropriate" (46\%). The percentage of confidence level in "deciding not to prescribe an antibiotic if the patient has fever but no severity criteria, and if you are not sure about your diagnosis" was 76\%, "choosing the correct antibiotic" was 76\%, "choosing between intravenous and oral administration" was 78\%, "interpreting microbiological results", and "planning to streamline/stop the antibiotic treatment according to clinical evaluation and investigations", 74\% was the average. The results are shown in Table 2.

\section{Training in antibiotic prescribing}

Out of 50, 42 interns answered "how many hours of training in principles of prudent antibiotic use" they had received in their undergraduate study (range $=8-540$,

Table I Demography of study population

\begin{tabular}{llllllll}
\hline Academic year & Sex & & & \multicolumn{2}{l}{ Age (years) } & Total \\
\cline { 2 - 3 } & Male & Female & & $\mathbf{2 2 - 2 4}$ & $\mathbf{2 5 - 2 8}$ & \\
\hline Intern doctor & 12 & 38 & & 15 & 35 & 50 \\
\hline
\end{tabular}


Table 2 Levels of confidence of antibiotics prescribing

\begin{tabular}{|c|c|c|c|c|c|}
\hline Areas of confidence in prescribing & $\begin{array}{l}\text { Very unconfident, } \\
\mathbf{N}(\%)\end{array}$ & $\begin{array}{l}\text { Unconfident, } \\
\mathbf{N}(\%)\end{array}$ & $\begin{array}{l}\text { Confident, } \\
\mathbf{N}(\%)\end{array}$ & $\begin{array}{l}\text { Very confident, } \\
\mathbf{N}(\%)\end{array}$ & $\begin{array}{l}\text { Uncertain, } \\
\mathbf{N}(\%)\end{array}$ \\
\hline Making an accurate diagnosis of infection/sepsis & 0 & $\mathrm{I}(2.0)$ & $45(90.0)$ & $3(6.0)$ & I (2.0) \\
\hline $\begin{array}{l}\text { Deciding not to prescribe an antibiotic if the patient } \\
\text { has fever but no severity criteria, and if you are not } \\
\text { sure about your diagnosis }\end{array}$ & 0 & $2(4.0)$ & $38(76)$ & $6(12)$ & $4(8)$ \\
\hline Choosing the correct antibiotic & 0 & $6(12)$ & $38(76)$ & $2(4)$ & $4(8)$ \\
\hline $\begin{array}{l}\text { Choosing the correct dose and interval of } \\
\text { administration }\end{array}$ & 0 & $2(4)$ & $42(84)$ & $6(12)$ & 0 \\
\hline Using a combination therapy if appropriate & 0 & $12(24)$ & $23(46)$ & $5(10)$ & $10(20)$ \\
\hline Choosing between IV and oral administration & 0 & $2(4)$ & $39(78)$ & $9(18)$ & 0 \\
\hline Interpreting microbiological results & 0 & $7(14)$ & $33(66)$ & $7(14)$ & $3(6)$ \\
\hline $\begin{array}{l}\text { Planning to streamline/stop the antibiotic treatment } \\
\text { according to clinical evaluation and investigations }\end{array}$ & 0 & $6(12)$ & $37(74)$ & $2(4)$ & $5(10)$ \\
\hline Planning the duration of the antibiotic treatment & 0 & $2(4)$ & $42(84)$ & $4(8)$ & $2(4)$ \\
\hline
\end{tabular}

Note: $\mathrm{N}=50$.

Abbreviation: IV, intravenous.

mean $=80.24 \pm 109.76)$. Almost, all of them $(\mathrm{N}=49,98 \%)$ would like more education on antibiotic selection at medical school. All respondents $(\mathrm{N}=50,100 \%)$ believed that prescribing inappropriate or unnecessary antibiotics was professionally unethical. In all, $58 \%(\mathrm{~N}=29)$ of the participants said that their hospital had antibiotic guidelines and $32 \%(\mathrm{~N}=16)$ indicated that there were no such guidelines. Sixty-four percent $(\mathrm{N}=32)$ of intern doctors never got a copy of their hospital's antibiotic guidelines or saw the said guidelines on the Internet. Sixty-six percent $(\mathrm{N}=33)$ of the subjects stated that they personally used or consulted antibiotic guidelines when considering an antibiotic for a patient. On the other hand, $32 \%(\mathrm{~N}=16)$ said that they never personally used or consulted antibiotic guidelines when considering an antibiotic for a patient.

\section{Knowledge that may shape perceptions of AR}

In all, 98\% $(\mathrm{N}=49)$ of the participants thought that antibiotic resistance was a national problem and $64 \%(\mathrm{~N}=32)$ thought that the same problem also existed in their own hospital. Thirty-four percent $(\mathrm{N}=17)$ stated that $21 \%-40 \%$ Staphylococcus aureus blood stream infections were due to methicillin-resistant Staphylococcus aureus (MRSA) in their country, whereas $28 \%(\mathrm{~N}=14)$ research participants answered $41 \%-60 \%$. The percentage was $1 \%-20 \%$, according to $38 \%(\mathrm{~N}=19)$ participants for the same situation 10 years back. Thirty-four percent $(\mathrm{N}=17)$ of total study population responded that $1 \%-20 \%$ S. aureus blood stream infections were due to Vancomycin-resistant $S$. aureus in their country. However, 24\% ( $\mathrm{N}=12)$ replied that $21 \%-40 \%$ infection recorded for the same situation. In all, $40 \%(\mathrm{~N}=20)$ of the participants responded that $1 \%-20 \%$ clinically relevant bacterial infections, excluding tuberculosis, in Bangladesh, were resistant to all known antibiotics.

\section{Antibiotic usage}

In all, $36 \%(\mathrm{~N}=18)$ of the participants claimed that $41 \%-60 \%$ of all antibiotic use could be attributed to hospital, compared with community use. Unnecessary or inappropriate antibiotic usage in Bangladesh was $41 \%-60 \%$ and $21 \%-40 \%$ according to $38 \%(\mathrm{~N}=19)$ and $30 \%(\mathrm{~N}=15)$ participants, respectively.

\section{Contributors to resistance}

Most of the intern doctors agreed that "too many antibiotic prescriptions", "too many broad spectrum antibiotics used", "excessive use of antibiotics in livestock", "poor hand hygiene", "not removing the focus of infection", and "paying too much attention to pharmaceutical representatives/ advertising" were very important factors contributing to AR (Table 3). Participants gave the opinion that "too long durations of antibiotic treatment" was slightly important and "dosing of antibiotics is too low" was moderately important to generate AR (Table 3).

\section{Development of antibiotics}

In all, 38\% ( $=19)$ of total subjects thought that 11-15 new classes of antibiotics were clinically available between 1980 and 2011 and $32 \%(\mathrm{~N}=16)$ participants supposed that more than 20 new classes would be available between 2011 and 2020. 
Table 3 Interns' view regarding contributors to resistance

\begin{tabular}{lllll}
\hline Contributors to resistance & $\begin{array}{l}\text { Very important, } \\
\text { N (\%) }\end{array}$ & $\begin{array}{l}\text { Moderately important, } \\
\text { N (\%) }\end{array}$ & $\begin{array}{l}\text { Slightly important, } \\
\text { N (\%) }\end{array}$ & $\begin{array}{l}\text { Not important at all, } \\
\text { N (\%) }\end{array}$ \\
\hline Too many antibiotic prescriptions & $33(66.0)$ & $3(6.0)$ & $1(2.0)$ & $13(26.0)$ \\
Too many broad spectrum antibiotics used & $30(60.0)$ & $8(16)$ & $2(4)$ & $10(20)$ \\
Too long durations of antibiotic treatment & $12(24)$ & $13(26)$ & $17(34)$ & $8(16)$ \\
Dosing of antibiotics are too low & $12(24)$ & $24(48)$ & $7(14)$ & $7(14)$ \\
Excessive use of antibiotics in livestock & $30(60)$ & $5(10)$ & $3(6)$ & $12(24)$ \\
Poor hand hygiene & $22(44)$ & $11(22)$ & $9(18)$ & $8(16)$ \\
Not removing the focus of infection & $33(66)$ & $7(14)$ & $9(18)$ & $1(2)$ \\
Paying too much attention to pharmaceutical & $21(42)$ & $8(16)$ & $12(24)$ & $9(18)$ \\
representatives/advertising & & & &
\end{tabular}

Note: $\mathrm{N}=50$.

\section{Perceptions of AR}

In all, 28\% ( $=14)$ and 26\% (N=13) of participating intern doctors thought that "deaths from road traffic accident" is 1.5-4 times and 4-8 times higher than AR, respectively. Thirty percent $(\mathrm{N}=15)$ of the respondents indicated that "deaths from lung cancer" is 1.5-4 times and 4-8 times higher than AR, respectively (Figures 1 and 2).

Fifty-two percent $(\mathrm{N}=26)$ of the participants felt that antibiotics prescribed by them as a doctor would "likely" contribute to the problem of resistance. Fifty-eight percent $(\mathrm{N}=29)$ of all study population thought that AR would "highly likely" be a greater problem in the future.

\section{Discussion}

Most of the study participants felt confident in "making an accurate diagnosis of infection/sepsis" (90\%), "choosing the correct dose and interval of administration", and "planning the duration of the antibiotic treatment" (84\%). This feature suggests that their clinical efficiency had improved during the internship period. These findings are similar with different

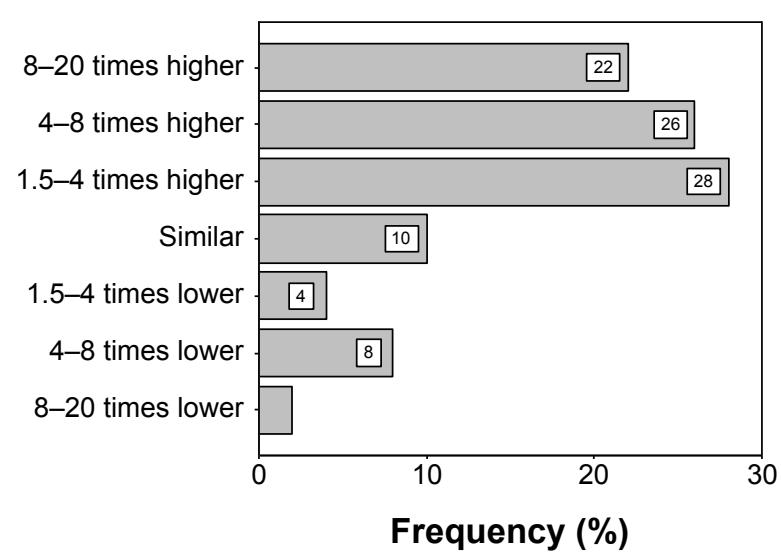

Figure I Interns' perception and comparison with death from RTA compared to AR.

Abbreviations: AR, antimicrobial resistance; RTA, road traffic accident. studies on junior doctors elsewhere in the world. ${ }^{14,17,35}$ It has been reported that misdiagnosis is a leading cause of unnecessary antibiotic prescriptions. ${ }^{16}$ Prescribing errors were common with interns due to a number of factors such as lack of drug knowledge, increased workload, poor guidelines, and inadequate supervision. ${ }^{36}$ The later findings were absent in the present study and can be attributed to the highly controlled and supervised environment of this teaching hospital. Our respondents (46\%) felt least confident in "using a combination therapy if appropriate". This is probably due to the fact that the combination is used especially in some selected cases by specialist physicians. Interns are directed to handle only common clinical problems. A special situation where a combination of drugs is needed requires supervision by the senior consultant physicians. Our findings seem to be similar to the study in Scotland. ${ }^{14}$

Almost, all of the intern doctors (98\%) would like more education on antibiotic selection at medical school. Our respondents realize the gaps in knowledge input and their clinical application of it clinically during their internship.

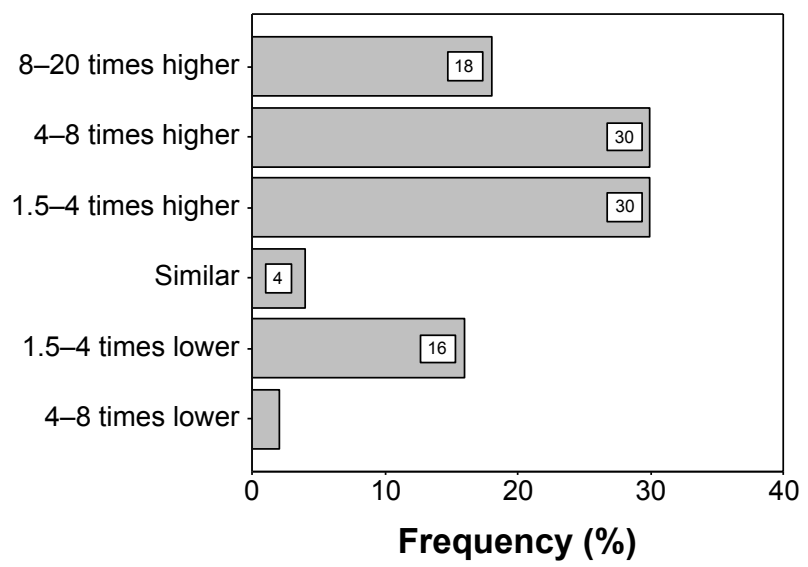

Figure 2 Interns' perception and comparison with death from lung cancer compared to AR.

Abbreviation: $A R$, antimicrobial resistance. 
In their undergraduate course, the interns were only taught theoretically about antibiotics with almost no practical clinical correlation or early clinical exposure. Study participants claimed that actual clinical practice is different and our study population indicates such a need. Similar reports were found in appraisals of doctors in teaching hospitals in both developing and developed countries. ${ }^{12,28}$

Most of the respondents (76\%) shared with the authors that they are in a dilemma about the selection of the best antibiotic for the treatment of infection. They also stated that each hospital follows their own antibiotic policies; currently there is neither a common national guideline nor a common drug policy plan for prescribing. The respondents (98\%) usually prescribe medications including antibiotics, emulating their senior peers, colleagues, and teachers. This phenomenon is practiced throughout Bangladesh and also many countries. ${ }^{37-39}$ Another area of concern is the continuous pressure and incentives offered by the pharmaceutical companies to select their brand of antibiotics. Similar findings reported that pharmaceutical gifts affect prescription practices of some physicians. ${ }^{7}$ Our respondents also believe that the availability of strict guidelines, resistance data, focus on education, and feedback on antibiotic resistance can help reduce the resistance pattern in Bangladesh. ${ }^{17}$ In all, $98 \%$ of the participants thought that antibiotic resistance was a national problem and $64 \%$ of the respondents thought that same problem also exists in their own hospital. These findings are more or less similar with other studies. ${ }^{7,13,14}$ However, few participants recognized AR as a problem in their own hospital. .,34 $^{-34}$

In the early 1960s, British scientists first reported the appearance of MRSA and by 1972 it accounted for 2\% of all health care-associated infections. ${ }^{40-43}$ Currently, MRSA has become widespread in hospitals of both developed and developing countries, especially worryingly in intensive care units. ${ }^{44,45}$ MRSA is a growing concern in the medical community. One Bangladeshi study reported an incidence of $37 \%$ and $22 \%$ MRSA among infected hospitalized and non-hospitalized diabetics, respectively. ${ }^{46}$ In all, $34 \%$ of the interns in this study stated that $21-40 \% \mathrm{~S}$. aureus blood stream infections were due to MRSA, whereas $28 \%$ answered that the percentage of the same was $41 \%-60 \%$. The percentage was $1 \%-20 \%$, according to $38 \%$ participants for the same situation 10 years back. In all, $34 \%$ of total study population responded that $1 \%-20 \%$ $S$. aureus blood stream infections were due to vancomycinresistant $S$. aureus in their country, however, 24\% replied that $21 \%-40 \%$ of infections were recorded for the same situation. Current study findings were quite similar with another similar study conducted in France and the UK. ${ }^{14}$
Hospital acquired infections also called nosocomial infection occurs worldwide (12\%) and affects both East Asia regions $(10 \%)$ with a prevalence of $8 \%$ and $9 \%$, respectively, in the European and Western Pacific regions. ${ }^{47}$ Though exact data are lacking in Bangladesh, probably the value is similar to South East Asian regions. In our study, 36\% participants claimed that $41 \%-60 \%$ of all antibiotic use occurred in hospital, compared with the community. This finding is similar to the study conducted in Ethopia where few participants recognized AR as a problem in their own hospital. ${ }^{7}$ These findings are consistent with studies conducted in previous studies from Sudan, West Indies, India, and Congo. ${ }^{48-51}$ Another Bangladeshi study results are consistent with current study findings. ${ }^{52}$

Unnecessary or inappropriate antibiotic usage in Bangladesh was $41 \%-60 \%$ and $21 \%-40 \%$ according to $38 \%$ and $30 \%$ participants, respectively. Health workers in many developing countries including Bangladesh have almost no access to objective health information. ${ }^{53,54}$ Overstatements and misinformation are common in Bangladesh, which greatly influence doctors' prescribing behaviors. ${ }^{55}$ It is reported that pharmaceutical industry sponsored information regarding medicine is the sole source of data and evidence for health professionals and bias toward their products. ${ }^{56-58}$ Questionable practices such as presentations of "gifts", sponsored vacations, and others inculcate a prescribing culture favoring the industry resulting in prescriptions of inappropriate or unnecessary and expensive medicines. ${ }^{59-61}$ These could also be the reasons in Bangladesh for inappropriate usage of medicine, including antimicrobials.

Most of the intern doctors agreed that "too many antibiotic prescriptions", "too many broad spectrum antibiotics used", "excessive use of antibiotics in livestock", "poor hand hygiene", "not removing the focus of infection", and "paying too much attention to pharmaceutical representatives/ advertising" were very important factors contributing to AR. Current study results were also supported by the findings of another Bangladeshi study. ${ }^{55}$ Present study findings are also similar to an Ethiopian and two other European studies. ${ }^{7,14,62}$ Hand washing has been shown to be the single most important factor in the prevention of transmission of infection in the hospital setting. ${ }^{61-64}$ Poor hand washing was well recognized in multiple studies as a contributor to bacterial drug resistance. ${ }^{14,18,43}$ Current study subjects were also aware of such contributors to resistance. This information could be important to help future doctors to recognize that actions taken by them individually could collectively lead to effective results to decrease AR. 
In all, $28 \%$ and $26 \%$ of the intern doctors thought that "deaths from road traffic accident" is 1.5-4 times and 4-8 times higher than AR. Thirty percent respondents said that "deaths from lung cancer" is 1.5-4 times and 4-8 times higher than AR. In a European study students totally overrated the relative burden of disease caused by resistant bacteria, with most suggesting it was similar to or higher than that of lung cancer. ${ }^{35}$ Death from any disease is confined to deceased person except death due to AR. In this case, victim is not the only end target but it might be the initiation of much greater tragedy. ${ }^{18,65,66} \mathrm{AR}$ not only causes treatment failure but also consumes more health care resources.

Fifty percent of the participants felt that antibiotics prescribed by them as a doctor would "likely" contribute to the problem of resistance. Fifty-eight percent of all study population thought that AR would "highly likely" be a greater problem later in their medical career. As most of the participants believed that their prescribing would contribute to the problem of antibiotic resistance, they could be encouraged to understand the relationship between inappropriate prescribing and ethical responsibility, and thus, their involvement in antibiotic stewardship efforts could be enhanced.

\section{Limitation of the study}

This is a cross-sectional study. Therefore, findings are only the snap-shot of the health care scenario in Bangladesh.

\section{Conclusion}

Despite the limitations of the cross-sectional study, the current study indicates the existing status of intern doctor's antimicrobial prescription competency and knowledge in AR. There is a gap between theoretical and clinical approach to antibiotic prescribing, which was viewed as a problem by the intern doctors. Ultimately, these findings can assist a better formulation of the medical curriculum, giving more emphasis on AR knowledge to medical students thus producing an AR-informed physician in the future.

Local guidelines must be made available to the intern doctors of CMOSHMC. Clinical competency during this stage of training is acquired mainly by emulating senior colleagues, who in turn might not be trained adequately to make the appropriate prescribing decision. Both national and local guidelines must be provided to give precise indications concerning intravenous-oral switch criteria, antibiotic combination choice criteria, and optimal duration of antibiotic treatment. All practicing doctors have to follow these guidelines strictly to improve their clinical competence.
Last but not the least, all health care professionals should work closely together to design sound workable strategies to contain AR.

\section{Acknowledgments}

The authors are grateful to all the participanting interns of CMOSHMC, Agrabad, Chittagong, Bangladesh, who have given their valuable time despite their busy duty schedule. We are also grateful to the Institutional Review Board and Principal of CMOSHMC, Agrabad, Chittagong, Bangladesh for all their help to conduct the study. This work was supported by the Institutional Review Board of CMOSHMC, Agrabad, Chittagong, Bangladesh and grant support from this institute. The current research was funded by CMOSHMC. The authors are also grateful to Dr Anwarul A Majumder, UK, and Dr S Parasuraman, Malaysia, for their kind cooperation during the study. Finally, we thank Dr Mohd Afandi Bin Muhamad, Malaysia, for his comments.

\section{Disclosure}

The authors report no conflicts of interest in this work.

\section{References}

1. Gopalakrishnan S, Ganeshkumar P, Katta A. Assessment of prescribing practices among urban and rural general practitioners in Tamil Nadu. Indian J Pharmacol. 2013;45(3):252-257.

2. Faiz MA, Ariful B. Antimicrobial resistance: Bangladesh experience. Reg Heal Forum. 2011;15(1):1-8.

3. Shanyerson M, Plotkin MJ. The Killer Within: The Deadly Rise of Drug-Resistant Bacteria. "A Compelling - If Terryfing - The Account of the Rise of Antibiotic Resistance". 1st ed. Boston: Little, Brown and Company; 2002:328.

4. Levy SB. The Antibiotic Paradox: How the Misuse of Antibiotics Destroys their Curative Powers. 2nd ed. Cambridge: Perseus Publishing; 2002:304.

5. WHO Global Strategy for Containment of Antimicrobial Resistance. World Health Organization; 2001. Available at: http://www.who.int/ drugresistance/WHO_Global_Strategy_English.pdf. Accessed May 10, 2015.

6. Togoobaatar G, Ikeda N, Ali M, et al. A survey of non-prescribed use of antibiotics for children in an urban community in Mongolia. Bull World Health Organ. 2010;88(12):930-936.

7. Abera B, Kibret M, Mulu W. Knowledge and beliefs on antimicrobial resistance among physicians and nurses in hospitals in Amhara Region, Ethiopia. BMC Pharmacol Toxicol. 2014;15(1):26.

8. Nyambayar K, Nakamura K, Ohnishi M, Nakajima R. Purchase of antimicrobials in retail pharmacies when a prescription is not required. J Rural Med. 2012;7(2):51-58.

9. Byarugaba DK. Antimicrobial resistance in developing countries and responsible risk factors. Int J Antimicrob Agents. 2004;24(2):105-110.

10. Grigoryan L, Burgerhof JGM, Degener JE, et al. Self-Medication with Antibiotics and Resistance (SAR) Consortium. Determinants of selfmedication with antibiotics in Europe: the impact of beliefs, country wealth and the healthcare system. J Antimicrob Chemother. 2008;61(5): 1172-1179.

11. Abbo L, Sinkowitz-Cochran R, Smith L, et al. Faculty and resident physicians' attitudes, perceptions, and knowledge about antimicrobial use and resistance. Infect Control Hosp Epidemiol. 2011;32(7):714-718. 
12. Srinivasan A, Song X, Richard A, Sinkowitz-Cochran R, Cardo D, Rand C. A survey of knowledge, attitudes, and beliefs of house staff physicians from various specialties concerning antimicrobial use and resistance. Arch Intern Med. 2004;164(13):1451-1456.

13. Wester CW, Durairaj L, Evans AT, Schwartz DN, Husain S, Martinez E. Antibiotic resistance: a survey of physician perceptions. Arch Intern Med. 2002;162(19):2210-2216.

14. Pulcini C, Williams F, Molinari N, Davey P, Nathwani D. Junior doctors' knowledge and perceptions of antibiotic resistance and prescribing: a survey in France and Scotland. Clin Microbiol Infect. 2011;17(1): 80-87.

15. Dellit TH, Owens RC, McGowan JE, et al. Infectious Diseases Society of America and the Society for Healthcare Epidemiology of America guidelines for developing an Institutional Program to enhance antimicrobial stewardship. Clin Infect Dis. 2007;44(2):159-177.

16. Pulcini C, Cua E, Lieutier F, Landraud L, Dellamonica P, Rooger PM. Antibiotic misuse: a prospective clinical audit in a French university hospital. Eur J Clin Microbiol Infect Dis. 2007;26(4):277-280.

17. Aggarwal S, Mathew J, Singh H, Sharma V. Attitude and perception of junior resident doctors' regarding antibiotic resistance - a pilot study. $J$ Acute Dis. 2014;3(1):6-9.

18. Centre for Disease Control and Prevention. Antibiotic Resistance Threats in the United States, 2013. Atlanta, Georgia: US Department of Health and Human Services; 2013:1-114.

19. Cabana MD, Rand CS, Powe NR, et al. Why don't physicians follow clinical practice guidelines? A framework for improvement. JAMA. 1999;282(15):1458-1465.

20. Schlipkoter U, Flahault A. Communicable diseases: achievements and challenges for public health. Public Health Rev. 2010;32(1):90-119.

21. Sivagnanam G, Thirumalaikolundusubramanian P, Mohanasundaram J, Raaj AA, Namasivayam K, Rajaram S. A survey on current attitude of practicing physicians upon usage of antimicrobial agents in southern part of India. Med Gen Med. 2004;6(2):1.

22. Williams A, Phillips A, Mathai A. Antibiotic prescription patterns at admission into a tertiary level intensive care unit in Northern India. J Pharm Bioallied Sci. 2011;3(4):531.

23. Oshikoya KA, Senbanjo IO, Amole OO. Interns' knowledge of clinical pharmacology and therapeutics after undergraduate and on-going internship training in Nigeria: a pilot study. BMC Med Educ. 2009;9:50.

24. Jorak A, Keihanian F, Saeidinia A, Heidarzadeh A, Saeidinia F. A cross sectional study on knowledge, attitude and practice of medical students toward antibiotic resistance and its prescription, Iran. Adv Environ Biol. 2014;8(17):675-681.

25. Khan AKA, Banu G, Reshma KK. Antibiotic resistance and usage-a survey on the knowledge, attitude, perceptions and practices among the medical students of a southern Indian teaching hospital. J Clin Diagn Res. 2013;7(8):1613-1616.

26. Wright EP, Jain P. Survey of antibiotic knowledge amongst final year medical students. J Antimicrob Chemother. 2004;53(3):550-551.

27. Simpson SA, Wood F, Butler CC. General practitioners' perceptions of antimicrobial resistance: a qualitative study. J Antimicrob Chemother. 2007;59(2):292-296.

28. Nitya S, Mangaiarkkarasi A, Meher AR, Sawadkar MS. Intern's knowledge of clinical pharmacology and therapeutics at Puducherry: a cross-sectional study. Int J Basic Clin Pharmacol. 2013;2(5): 622 .

29. Dean B, Schachter M, Vincent C, Barber N. Causes of prescribing errors in hospital inpatients: a prospective study. Lancet. 2002;359(9315): 1373-1378

30. Bhavsar VH. Experiences regarding modification of the teaching and evaluation pattern in practical pharmacology. Indian J Pharmacol. 2004; 36(6):385-389.

31. Islam Z, Rahman F, Mossaddek AS, et al. Assessment of Bangladeshi interns' knowledge of pharmacology and therapeutics for prescribing. J Appl Pharm Sci. 2014;4(4):43-51.

32. Pulcini C, Gyssens IC. How to educate prescribers in antimicrobial stewardship practices. Virulence. 2013;4(2):192-202.
33. World Health Organization (WHO). The World Medicines Situation. Geneva: WHO; 2004:5-22.

34. Butler CC, Rollnick S, Pill R, Maggs-Rapport F, Stott N. Understanding the culture of prescribing: qualitative study of general practitioners' and patients' perceptions of antibiotics for sore throats. BMJ. 1998;317(7159):637-642.

35. Dyar OJ, Pulcini C, Howard P, Nathwani D. European medical students: a first multicentre study of knowledge, attitudes and perceptions of antibiotic prescribing and antibiotic resistance. J Antimicrob Chemother. 2014;69(3):842-846.

36. Coombes ID, Stowasser DA, Coombes JA, Mitchell C. Why do interns make prescribing errors? A qualitative study. Med J Aust. 2008; 188(2):89-94.

37. Hogerzeil HV, Barnes KI, Henning RH, et al. Teacher's Guide to Good Prescribing. Geneva: World Health Organization Department of Essential Drugs and Medicines Policy; 2001:1-106.

38. De Vries TPGM, Henning RH, Hogerzeil HV, Fresle DA. Guide to Good Prescribing - A Practical Manual. Geneva: World Health Organization; 2000:142.

39. Management Sciences for Health. Promoting rational prescribing. Pharmaceut Manag. 2012:29.1-29.23.

40. Chambers HF. Methicillin resistance in staphylococci: molecular and biochemical basis and clinical implications. Clin Microbiol Rev. 1997;10(4):781-791.

41. Barber M. Methicillin-resistant staphylococci. J Clin Pathol. 1961;14(4): 385-393.

42. Borowski J, Kamieiska K, Ruteka I. Methicillin-resistant Staphylococci. Brit Med J. 1964;1(5388):983.

43. Jevons MP, Coe AW, Parker MT. Methicillin resistance in Staphylococci. Lancet. 1963;1(7287):904-907.

44. Diekema DJ, BootsMiller BJ, Vaughn TE, et al. Antimicrobial resistance trends and outbreak frequency in United States hospitals. Clin Infect Dis. 2004;38(1):78-85.

45. Boucher HW, Corey GR. Epidemiology of methicillin-resistant Staphylococcus aureus. Clin Infect Dis. 2008;46(Suppl 5):S344-S349.

46. Jinnah F, Chowdhury K, Begum J, et al. Multi-resistant Staphylococcus aureus isolated from the wound of diabetic patients. J Infect Dis Antimicrob Agents. 1998;15:15-18.

47. World Health Organization (WHO). Prevention of hospital-acquired infections. A practical guide. In: Ducel G, Fabry J, Nicolle L, editors. World Health Organization. Malta: The World Health Organization; 2002:1-64.

48. Kheder SI. Physicians' knowledge and perception of antimicrobial resistance: a survey in Khartoum State Hospital Settings. Br J Pharm Res. 2013;3(3):347-362.

49. Tennant I, Nicholson A, Gordon-Strachan GM, Thoms C, Chin V, Didier MA. A survey of physicians' knowledge and attitudes regarding antimicrobial resistance and antibiotic prescribing practices at the University Hospital of the West Indies. West Indian Med J. 2010;59(2):165-170.

50. Qavi A, Segal-Maurer S, Mariano N, et al. Increased mortality associated with a clonal outbreak of ceftazidime-resistant Klebsiella pneumoniae: a case-control study. Infect Control Hosp Epidemiol. 2005;26(1):63-68.

51. Thriemer K, Katuala Y, Batoko B, et al. Antibiotic prescribing in DR Congo: a knowledge, attitude and practice survey among medical doctors and students. PLoS One. 2013;8(2):e55495.

52. Gurley ES, Zaman RU, Sultana R, et al. Rates of hospital-acquired respiratory illness in Bangladeshi tertiary care hospitals: results from a low-cost pilot surveillance strategy. Clin Infect Dis. 2010;50(8): 1084-1090.

53. Vital Wave Consultancy. Health Information Systems in Developing Countries. Palo Alto, CA, USA: Vital Wave Consulting; 2009.

54. Cash R. Inappropriate treatment for dysentery. BMJ. 1996;313(7051): 181-182.

55. Sutradhar KB, Saha A, Huda NH, Uddin R. Irrational use of antibiotics and antibiotic resistance in Southern Rural Bangladesh: perspectives from both the physicians and patients. Annu Res Rev Biol. 2014;4(9):1421-1430. 
56. Ronsmans C, Islam T, Bennish ML. Medical practitioners' knowledge of dysentery treatment in Bangladesh. BMJ. 1996;313(7051):205-206.

57. Parr J, Lindeboom W, Khanam M, Sanders J, Koehlmoos TP. Informal allopathic provider knowledge and practice regarding hypertension in urban and rural Bangladesh. PLoS One. 2012;7(10):1-9.

58. Khan A. State minister's negligence worries us. The Daily Obsever. 2015;1. Available from: http://www.observerbd.com/2015/02/16/72830. php\#. Accessed June 1, 2015.

59. Bangladesh Enterprise Institute. Country Report: Bangladesh. Dhaka: Bangladesh Enterprise Institute; 2005. Available from: http://www. cuts-international.org/7up2/Country_report_Bangladesh.doc. Accessed June 1, 2015.

60. Islam MS. A review on the policy and practices of therapeutic drug uses in Bangladesh. Calicut Med J. 2006;4(4):e2.

61. Islam MS. Therapeutic drug use in Bangladesh: policy versus practice. Indian J Med Ethics. 2008;5(1):24-25.

62. Navarro-San Francisco C, Del Toro MD, Cobo J, et al. Knowledge and perceptions of junior and senior Spanish resident doctors about antibiotic use and resistance: results of a multicenter survey. Enferm Infecc Microbiol Clin. 2013;31(4):199-204.
63. SARI Infection Control Subcommittee. Guidelines for Hand Hygiene in Irish Health Care Settings. Published on behalf of SARI by HSE, Health Protection Surveillance Centre. SARI Infection Control Subcommittee; 2004:1-51. Available from: https://www.hpsc.ie/A-Z/MicrobiologyAntimicrobialResistance/InfectionControlandHAI/Guidelines/ File,1047,en.pdf. Accessed June 1, 2015.

64. Centers for Disease Control and Prevention. Guideline for hand hygiene in health-care settings: recommendations of the Healthcare Infection Control Practices Advisory Committee and the HICPAC/SHEA/APIC/ IDSA Hand Hygiene Task Force. MMWR Recomm Rep. 2002;51:1-45, quiz CE1-E4.

65. Infectious Diseases Society of America. Bad Bugs, No drugs As Antibiotic Discovery Stagnates...A public Health Crisis Brews. Arlington, VA, USA: Infectious Diseases Society of America; 2004:1-35.

66. Boucher HW, Talbot GH, Bradley JS, et al. Bad bugs, no drugs: no ESKAPE! An update from the Infectious Diseases Society of America. Clin Infect Dis. 2009;48(1):1-12.
Therapeutics and Clinical Risk Management

\section{Publish your work in this journal}

Therapeutics and Clinical Risk Management is an international, peerreviewed journal of clinical therapeutics and risk management, focusing on concise rapid reporting of clinical studies in all therapeutic areas, outcomes, safety, and programs for the effective, safe, and sustained use of medicines. This journal is indexed on PubMed Central, CAS,

\section{Dovepress}

EMBase, Scopus and the Elsevier Bibliographic databases. The manuscript management system is completely online and includes a very quick and fair peer-review system, which is all easy to use. Visit http://www.dovepress.com/testimonials.php to read real quotes from published authors.

Submit your manuscript here: http://www.dovepress.com/therapeutics-and-clinical-risk-management-journal 